\title{
Magnetic clusters in ilmenite-hematite solid solutions
}

Frandsen, Cathrine; Burton, B. P.; Rasmussen, Helge Kildahl; McEnroe, S. A.; Mørup, Steen

\section{Published in:}

Physical Review B Condensed Matter

Link to article, DOI:

10.1103/PhysRevB.81.224423

Publication date:

2010

Document Version

Publisher's PDF, also known as Version of record

Link back to DTU Orbit

Citation (APA):

Frandsen, C., Burton, B. P., Rasmussen, H. K., McEnroe, S. A., \& Mørup, S. (2010). Magnetic clusters in ilmenite-hematite solid solutions. Physical Review B Condensed Matter, 81(22), 224423.

https://doi.org/10.1103/PhysRevB.81.224423

\section{General rights}

Copyright and moral rights for the publications made accessible in the public portal are retained by the authors and/or other copyright owners and it is a condition of accessing publications that users recognise and abide by the legal requirements associated with these rights.

- Users may download and print one copy of any publication from the public portal for the purpose of private study or research.

- You may not further distribute the material or use it for any profit-making activity or commercial gain

- You may freely distribute the URL identifying the publication in the public portal

If you believe that this document breaches copyright please contact us providing details, and we will remove access to the work immediately and investigate your claim 


\title{
Magnetic clusters in ilmenite-hematite solid solutions
}

\author{
C. Frandsen, ${ }^{1, *}$ B. P. Burton, ${ }^{2}$ H. K. Rasmussen, ${ }^{1}$ S. A. McEnroe, ${ }^{3}$ and S. Mørup ${ }^{1}$ \\ ${ }^{1}$ Department of Physics, Technical University of Denmark, DK-2800 Kongens Lyngby, Denmark \\ ${ }^{2}$ NIST, 100 Bureau Drive, Gaithersburg, Maryland 20878, USA \\ ${ }^{3}$ Geological Survey of Norway, N-7491 Trondheim, Norway
}

(Received 22 May 2010; published 16 June 2010)

\begin{abstract}
We report the use of high-field ${ }^{57} \mathrm{Fe}$ Mössbauer spectroscopy to resolve the magnetic ordering of ilmenitehematite $\left[x \mathrm{FeTiO}_{3}-(1-x) \mathrm{Fe}_{2} \mathrm{O}_{3}\right]$ solid solutions with $x>0.5$. We find that nanometer-sized hematite clusters exist within an ilmenite-like matrix. Although both phases are antiferromagnetically ordered, the hematite clusters show ferrimagnetic behavior due to superexchange coupling with $\mathrm{Fe}^{2+}$ in ilmenite. For ilmenite-rich samples $(x=0.95)$, the clusters are isolated and superparamagnetic. For more hematite-rich samples with $x$ $=0.80$ and $x=0.70$, the clusters interact to form a cluster glass.
\end{abstract}

DOI: 10.1103/PhysRevB.81.224423

PACS number(s): 75.50.Tt, 76.80.+y, 91.25.F-

\section{INTRODUCTION}

The ilmenite-hematite $\left[x \mathrm{FeTiO}_{3}-(1-x) \mathrm{Fe}_{2} \mathrm{O}_{3}\right]$ solid solution series has attracted significant attention because of its complex magnetic and electronic properties. Both ilmenite $\left(\mathrm{FeTiO}_{3}\right)$ and hematite $\left(\alpha-\mathrm{Fe}_{2} \mathrm{O}_{3}\right)$ are antiferromagnetic and insulating but intermediate compositions can be ferrimagnetic and semiconducting. ${ }^{1-15}$ The system is of significant interest as a source of natural remnant magnetism on the earth, the moon, and the planet Mars. ${ }^{8-11}$ It is also considered promising for spintronics applications. ${ }^{13-15}$ The semiconducting properties can be controlled as $p$ or $n$ type by varying the composition, and it has been demonstrated that for $x=0.6$ the carrier spins are polarized at room temperature. ${ }^{13}$ A detailed understanding of the magnetic and $\mathrm{Fe}^{2+} / \mathrm{Fe}^{3+}$ charge ordering in ilmenite-hematite is therefore of great importance.

Ilmenite and hematite both have rhombohedral crystal structures. The complex magnetic properties of their solid solutions derive from incompatibilities between their different modes of cation and magnetic ordering. In ilmenite, $\mathrm{Fe}^{2+}$ A layers alternate with $\mathrm{Ti}^{4+} \mathrm{B}$ layers along the rhombohedral [111] axis. Adjacent $\mathrm{Fe}^{2+} \mathrm{A}$ layers have opposite magnetization directions parallel to [111], and the Néel temperature of ilmenite is around $55 \mathrm{~K}^{2}$ In hematite, $\mathrm{Fe}^{3+}$ occupies both A and $\mathrm{B}$ layers with antiferromagnetic coupling between adjacent layers. Hence the antiferromagnetic modulation length of hematite is about half that of ilmenite. The Néel temperature of hematite is about $955 \mathrm{~K}^{2}$ Above $263 \mathrm{~K}$ (the Morin transition temperature), or in samples with small grain size $(<20 \mathrm{~nm})$, or with $(>1 \%) \mathrm{Ti}^{4+}$ substitution, ${ }^{16}$ the sublattice magnetization directions of hematite are perpendicular to [111] with a small canting of the two sublattices. This results in weak ferromagnetism (canted antiferromagnetism) of $\sim 0.4 \mathrm{~A} \mathrm{~m}^{2} / \mathrm{kg}$, with the net magnetization nearly perpendicular to the sublattice magnetization directions. In pure bulk hematite below $263 \mathrm{~K}$ the sublattice magnetization is along [111]. Owing to immiscibility of ilmenite and hematite below $\sim 1000 \mathrm{~K}$, exsolution of near end-member phases occurs upon slow cooling. ${ }^{8-11}$ Rapid cooling quenches metastable solid solutions. ${ }^{1-7}$

Previous measurements have revealed the overall magnetic properties of the ilmenite-hematite system (for phase diagrams see Refs. 6 and 7) but at the atomic scale, the magnetic ordering remains largely unresolved. ${ }^{7,9,15}$ For 0.5 $\vdots x<1.0$ magnetization measurements show that solid solutions are significantly magnetic, up to more than $\sim 30 \mathrm{~A} \mathrm{~m}^{2} / \mathrm{kg}$ for compositions of $x \sim 0.6-0.7,{ }^{1-3}$ due to $\mathrm{Fe}^{3+}$ (or $\mathrm{Fe}^{2+}$ ) ions substituting for $\mathrm{Ti}^{4+}$ in the B layers, resulting in a ferrimagnetic structure. ${ }^{2,4,17}$ Neutron diffraction has shown that for $0.5 \leqq x<1.0$ essentially all $\mathrm{Ti}^{4+}$ is in the $\mathrm{B}$ layers but the cation distribution within layers is inhomogenous. ${ }^{5}$ Magnetization measurements suggest that small magnetic clusters exist, with long-range magnetic correlations beyond a percolation threshold of $x \leq 0.87$. . $^{71}$ However, the details of $\mathrm{Fe}^{2+} / \mathrm{Fe}^{3+}$ charge-ordered cation distribution and their implications for magnetic ordering are yet to be clarified.

To determine the local structure and magnetic properties, we performed high-field ${ }^{57} \mathrm{Fe}$-Mössbauer studies of ilmeniterich solid solutions with $x=0.95, x=0.80$, and $x=0.70$. Highfield Mössbauer studies can elucidate both cation distributions in ferrimagnets ${ }^{18}$ and superparamagnetic relaxation phenomena. ${ }^{19-21}$

\section{EXPERIMENTAL DETAILS}

Samples with nominal compositions of $x=0.95,0.80$, and 0.70 were prepared by heating mixtures of $\mathrm{Fe}_{2} \mathrm{O}_{3}$ and $\mathrm{TiO}_{2}$ in $\mathrm{Ag}$ foils, sealed into silica tubes, at $900-920{ }^{\circ} \mathrm{C}$ followed by rapid cooling (for details see Refs. 7 and 22). The samples are referred to as Ilm95, Ilm80, and Ilm70. The X-ray diffraction analysis given in Ref. 7 shows that $\operatorname{Ilm} 95$ is a pure rhombohedral phase of ilmenite-hematite while Ilm70 is almost purely rhombohedral with a small impurity of an unidentified phase. Unpublished data of Ilm80 indicates a pure ilmenite-hematite sample. In Ref. 7, Ilm95 and Ilm70 compositions have been redetermined by use of $\mathrm{x}$-ray diffraction and corresponding samples are listed as Ilm97.4 and Ilm71.0.

Mössbauer spectra were obtained using a conventional constant acceleration spectrometer with a source of ${ }^{57} \mathrm{Co}$ in rhodium. Isomer shifts are given relative to $\alpha$-Fe at $295 \mathrm{~K}$. Spectra with and without a magnetic field of $6 \mathrm{~T}$, applied parallel to the gamma-ray propagation direction, were ob- 

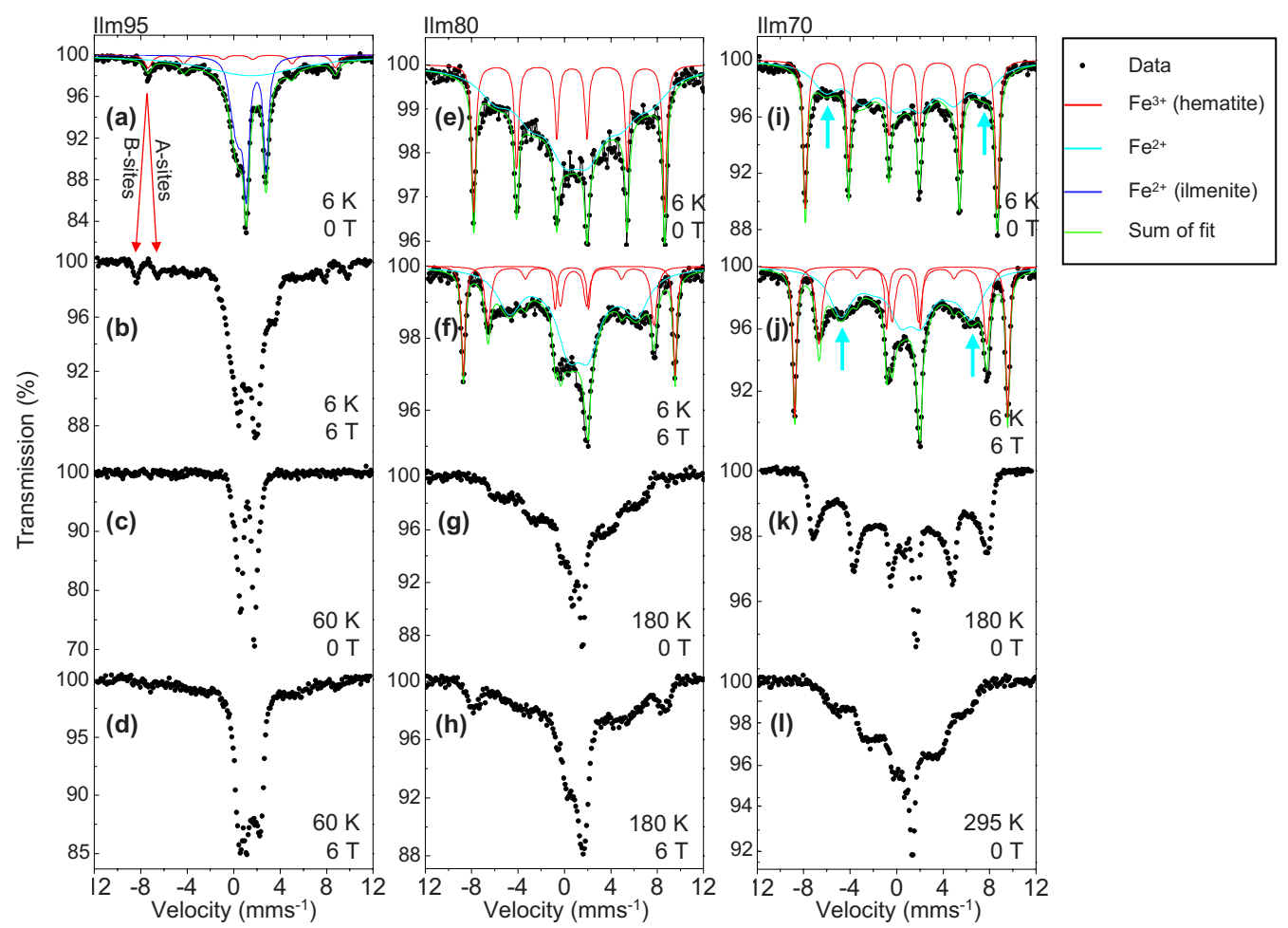

FIG. 1. (Color online) Mössbauer spectra of Ilm95, Ilm80, and Ilm70 at different temperatures and in zero (0 T) or $6 \mathrm{~T}$ applied field as indicated. Colored lines represent fits to data.

tained using a liquid-helium cryostat with a superconducting coil.

\section{RESULTS AND DISCUSSION}

Figure 1 shows Mössbauer spectra of Ilm95, Ilm80, and Ilm70. Zero-field spectra obtained at $6 \mathrm{~K}$ [Figs. 1(a), 1(e), and 1(i)] show the presence of a magnetic (six-line) component (red fit) with a magnetic hyperfine field of $50.0 \mathrm{~T}$ in Ilm95, 51.0 T in Ilm80, and 51.2 T in Ilm70. In Ilm80 and Ilm70 the isomer shifts of this sextet are $0.53 \mathrm{~mm} \mathrm{~s}^{-1}$ and the quadrupole shifts are $-0.11 \mathrm{~mm} \mathrm{~s}^{-1}$, which are very close to the values for $\mathrm{Fe}^{3+}$ in pure hematite with the sublattice magnetization perpendicular to $[111] .^{21}$ The hyperfine fields are slightly smaller than that of pure hematite $\left(B_{\mathrm{hf}}\right.$ $\sim 53 \mathrm{~T}){ }^{20}$ This may be explained by the presence of $\mathrm{Ti}^{4+}$ in the hematite or by magnetic relaxation effects..$^{20,21,23}$ It is reasonable to assume that these components in Figs. 1(a), 1(e), and 1(i) are all due to $\mathrm{Fe}^{3+}$ in hematite-like environments, and hence that their isomer shifts are nearly identical. By comparing the line positions of lines 1 and 6 of the hematite sextets in Figs. 1(a), 1(e), and 1(i) we can estimate the quadrupole shift in Ilm95 as $\varepsilon=+0.2 \pm 0.02 \mathrm{~mm} \mathrm{~s}^{-1}$. This shows that the sublattice magnetization of the hematite-like component in Ilm95 is actually parallel to [111] at low temperature, ${ }^{21}$ in agreement with neutron studies on a sample with $x=0.90 .^{24}$

The $6 \mathrm{~T}$ spectra [Figs. 1(b), 1(f), and 1(j)] were obtained at $6 \mathrm{~K}$ with the magnetic field applied parallel to the gammaray direction. Remarkably, the hematite sextets seen in the zero-field spectra have transformed into two sextets. This is surprising because application of large applied fields to antiferromagnetic hematite at temperatures below $T_{M}$ results only in some line broadening in the Mössbauer spectra. ${ }^{25}$ Moreover, high-field Mössbauer studies ${ }^{20}$ of canted antiferromagnetic hematite nanoparticles have shown that the small net magnetic moment due to canting was aligned with the applied field, such that the sublattice magnetization directions become nearly perpendicular to the field, and the spectra therefore consist of a single sextet with relatively narrow lines and a magnetic splitting close to that of the zero-field spectra. ${ }^{20}$ Thus, the behavior of the hematite components in the high-field spectra in Figs. 1(b), 1(f), and 1(j) is clearly different from that of antiferromagnetic and canted antiferromagnetic hematite, and it indicates that the hematite in the three samples responds ferrimagnetically to an applied field. In Ilm95 the magnetic hyperfine fields of these sextets are 56.3 and $44.7 \mathrm{~T}$, in Ilm80 they are 56.6 and $44.3 \mathrm{~T}$, and in $\operatorname{Ilm} 70,56.8$ and $44.6 \mathrm{~T}$. Within uncertainty $(\sim \pm 0.5 \mathrm{~T})$ these magnetic hyperfine fields correspond to the values in the zero-field spectra $\pm 6 \mathrm{~T}$. Also, lines 2 and 5 of the zerofield spectra are much less intense in the $6 \mathrm{~T}$ spectra [Figs. 1(b), 1(f), and 1(j)]. This shows that the sublattice magnetizations of the hematite components are either nearly parallel or antiparallel to the applied field.

The hematite components with larger hyperfine fields in the $6 \mathrm{~T}$ spectra correspond to $\mathrm{Fe}^{3+}$ in the minority sublattices, i.e., the B layers in the model of Ishikawa et al. ${ }^{2,6}$ because the magnetic hyperfine field of $\mathrm{Fe}^{3+}$ is antiparallel to the magnetic moment. If we assume that all $\mathrm{Ti}^{4+}$ is in the $\mathrm{B}$ layers, and that $\mathrm{Fe}^{3+}$ is equally distributed between $\mathrm{A}$ and $\mathrm{B}$ layers, we can write the chemical composition as $\left(\mathrm{Fe}_{x}^{2+}, \mathrm{Fe}_{1-x}^{3+}\right)_{\mathrm{A}-\mathrm{site}}\left(\mathrm{Ti}_{x}^{4+}, \mathrm{Fe}_{1-x}^{3+}\right)_{\mathrm{B}-\text { site }} \mathrm{O}_{3}$. Hence, the number of $\mathrm{B}$ 
sites available for iron in Ilm95 corresponds to $2.5 \%$ of the total number of cations, i.e., $4.8 \%$ of the iron ions. The relative area of the $\mathrm{Fe}^{3+}$ component with larger hyperfine field [Fig. 1(b)] is $4.5 \% \pm 1.0 \%$. Thus, within uncertainty, these data accord with a model in which all $\mathrm{Ti}^{4+}$ is in $\mathrm{B}$ sites and all $\mathrm{Fe}$ in $\mathrm{B}$ sites is $\mathrm{Fe}^{3+}$. The $\mathrm{Fe}^{3+}$ component in the majority sublattice (A layers) has a relative area of $4.0 \% \pm 1.0 \%$, i.e., close to the expected $4.8 \%$. A similar analysis of the $6 \mathrm{~T}$ spectrum of Ilm80 showed that $14_{-2}^{+4} \%$ and $12_{-2}^{+4} \%$ of the iron atoms are present as $\mathrm{Fe}^{3+}$ in the $\mathrm{B}$ and $\mathrm{A}$ sites, respectively. The expected values are $16.6 \%$. The Mössbauer spectrum of Ilm70 [Fig. 1(j)] shows that around $20 \%$ of the iron is $\mathrm{Fe}^{3+}$ in $\mathrm{B}$ sites and around $20 \%$ is $\mathrm{Fe}^{3+}$ in A sites; theoretical values are $23 \%$. The uncertainties given above are estimated from variations in the parameters of fits with different constraints. Due to line overlaps, the estimates are likely to be on the low side of the actual values. In all three cases the $\mathrm{Fe}^{3+}$ seems to be equally distributed between $\mathrm{A}$ and $\mathrm{B}$ layers. The above analyses of relative areas also indicate that, within uncertainty, measured and nominal compositions are equal.

The sextet component with relatively sharp lines at low velocities in the $6 \mathrm{~K}$ spectrum of Ilm95 [Fig. 1(a), blue-line fit] is typical of ilmenite. The zero-field $6 \mathrm{~K}$ spectra also contain some very broad components and in Ilm80 and Ilm70 they can be fitted with sextets [shown by turquoise lines in Figs. 1(e) and 1(i)] with broad lines and isomer shifts around $0.7-1.1 \mathrm{~mm} \mathrm{~s}^{-1}$, and hyperfine fields up to about 25-42 T. Such values suggest that these components are (mainly) due to $\mathrm{Fe}^{2+}$ but in a distribution of local environments that differ from that of pure ilmenite, in which the magnetic hyperfine field is only $\sim 5 \mathrm{~T}$. The magnetic hyperfine field of $\mathrm{Fe}^{2+}$ is very sensitive to the atomic environment because of the influence of the orbital magnetic moment on the hyperfine field. In pure ilmenite, the orbital, dipolar, and the Fermi contributions to the hyperfine field nearly cancel, and this explains the small value of the total hyperfine field. ${ }^{26}$ In the spectra of Ilm80 [Fig. 1(e)] and Ilm70 [Fig. $1(\mathrm{i})]$, these broad components with hyperfine fields up to 25-40 K account for the majority of the $\mathrm{Fe}^{2+}$ in the samples. When a magnetic field of $6 \mathrm{~T}$ is applied at $6 \mathrm{~K}$, the $\mathrm{Fe}^{2+}$ components become better resolved, most distinctly seen for Ilm70. Due to the broad lines it is difficult to determine the exact line positions but assuming the positions of lines 1 and 6 to be as marked by arrows in Figs. 1(i) and 1(j), we find that the hyperfine fields decrease by approximately $6 \mathrm{~T}$ with applied field. This supports the interpretation that the $\mathrm{Fe}^{2+}$ ions in Ilm80 and Ilm70 are in the A layers. Additionally, it shows that the $\mathrm{Fe}^{2+}$ moments are aligned nearly parallel to the applied field.

The zero-field spectrum of Ilm95 at $60 \mathrm{~K}$ [Fig. 1(c)] only exhibits doublets, indicating the presence of paramagnetic ions or superparamagnetic clusters. However, in the $6 \mathrm{~T}$ spectrum at $60 \mathrm{~K}$ [Fig. 1(d)] there is a very broad component, indicating a distribution of hyperfine fields with values up to $\sim 50 \mathrm{~T}$. For paramagnetic iron ions with magnetic moments on the order of a few Bohr magneton the induced magnetization at $60 \mathrm{~K}$, in an applied field of $6 \mathrm{~T}$, is small and cannot explain the appearance of the very broad component. However, superparamagnetic clusters with magnetic moments on the order of $100 \mu_{\mathrm{B}}$ will be nearly magnetically saturated, and will therefore contribute magnetically split components with large hyperfine fields. Thus, the $60 \mathrm{~K}$ spectrum shows unambiguously that the sample contains superparamagnetic clusters, in agreement with magnetization measurements. ${ }^{7,17}$ Theoretical modeling lends support to cluster formation. ${ }^{27,28}$ The maximum hyperfine fields $(\sim 50 \mathrm{~T})$, estimated from the broad component in the $6 \mathrm{~T}$ spectrum, are larger than $90 \%$ of the saturation hyperfine field of hematite $(\sim 53 \mathrm{~T})$. Assuming that the magnetization of a superparamagnetic cluster in an applied magnetic field is approximately proportional to the Langevin function, we find that the largest clusters have magnetic moments of at least $150 \mu_{\mathrm{B}}$. From magnetization measurements, average cluster moments of $44 \mu_{\mathrm{B}}$ and $228 \mu_{\mathrm{B}}$ have been estimated for $x$ $=0.92$ and $x=0.88$, respectively. ${ }^{17}$

The zero-field spectrum of Ilm80 at $180 \mathrm{~K}$ [Fig. 1(g)] and the spectrum of Ilm70 at $295 \mathrm{~K}$ [Fig. 1(1)] are dominated by sextet components with very broad lines. These broad components have similarities to Mössbauer relaxation spectra and might be ascribed to superparamagnetic grains with relaxation times on the order of $10^{-9}-10^{-8} \mathrm{~s}$. However, because of the inevitable particle size distribution in samples of noninteracting hematite nanoparticles, there is usually a wide distribution of superparamagnetic relaxation times and the spectra therefore consist of a superposition of sextets and doublets with narrow lines. ${ }^{20,21,23,29}$ In samples of hematite nanoparticles in close proximity, the exchange interactions between surface atoms may result in freezing of the magnetic moments of the particles in a superferromagnetic or superspin glass. ${ }^{21,23,29}$ At finite temperatures the sublattice magnetization then fluctuates around a direction that is mainly defined by an interaction field. Variations in the strengths of interparticle interactions results in spectra with a distribution of hyperfine fields, and this gives rise to spectra with sextet components with broad asymmetric lines like those in Figs. $1(\mathrm{~g}), 1(\mathrm{k})$, and 1(1). ${ }^{21,23,29}$ Similar observations have been made in Mössbauer studies of interacting nanoparticles of ferrihydrite (Ref. 30) and ${ }^{57} \mathrm{Fe}$-doped $\mathrm{NiO}$ (Refs. 31 and 32).

Upon application of a $6 \mathrm{~T}$ magnetic field to Ilm80 at 180 $\mathrm{K}$, the outer lines of the sextet become better resolved [see Fig. 1(h)], and the magnetic splitting increases from $\sim 40$ to $\sim 51$ T, i.e., much more than what one expects from the applied field alone. This shows that the magnetic fluctuations are suppressed. ${ }^{21,23}$ Thus the data for Ilm70 and Ilm80 favor an interpretation based on interacting superparamagnetic clusters, ${ }^{23}$ i.e., a cluster glass. ${ }^{6,17}$

The spectra of Ilm80 and Ilm70 at 180 and 295 K [Figs. $1(\mathrm{~g}), 1(\mathrm{~h}), 1(\mathrm{k})$, and 1(1)] are asymmetric, showing more absorption in the range $\sim 3-6 \mathrm{~mm} \mathrm{~s}^{-1}$ than in the corresponding negative velocity range. This is due to contributions to the spectra from $\mathrm{Fe}^{2+}$ that has a larger isomer shift than $\mathrm{Fe}^{3+}$. The observation that the $\mathrm{Fe}^{2+}$ in the ilmenite-like matrix shows a magnetically split spectrum at temperatures well above the Néel temperature of bulk ilmenite indicates that some of the $\mathrm{Fe}^{2+}$ in ilmenite is not paramagnetic. It is likely that exchange interactions with $\mathrm{Fe}^{3+}$ in the hematite clusters have increased the ordering temperature of thin layers of ilmenite surrounding the hematite. A similar effect has been seen in multilayer structures of $\mathrm{Fe}_{3} \mathrm{O}_{4} / \mathrm{CoO}$ in which the Néel temperature of $\mathrm{CoO}$ is enhanced due to the proximity of magnetic $\mathrm{Fe}_{3} \mathrm{O}_{4}$ layers (Ref. 33). 


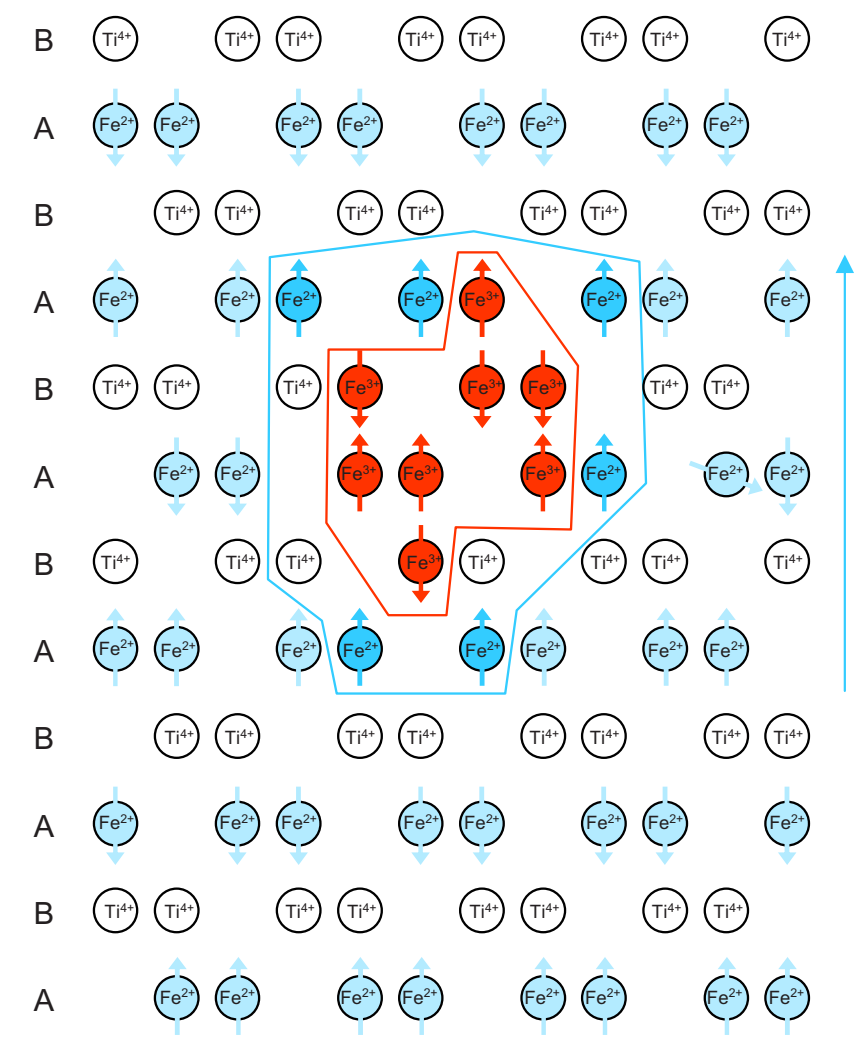

(a)

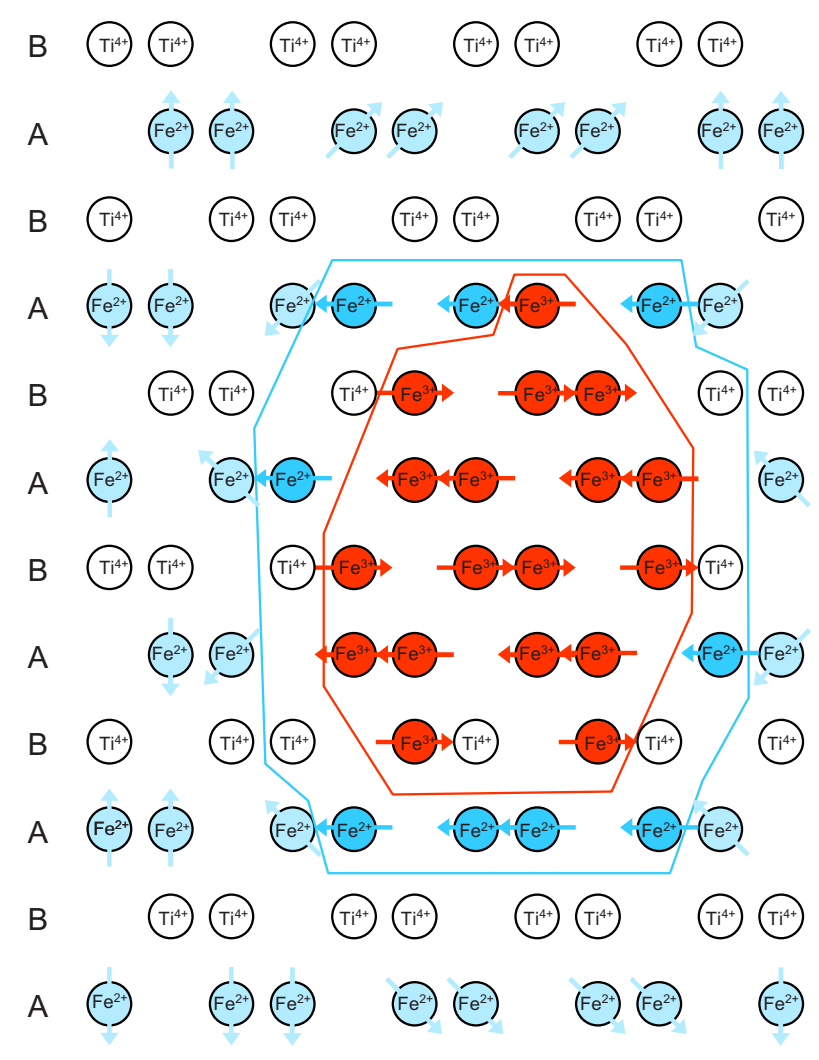

(b)

FIG. 2. (Color online) Schematic representation of cluster formation in Ilm95 and Ilm80. (a) Fe ${ }^{3+}$ ions in Ilm95 form isolated antiferromagnetic clusters (red - dark gray in print - arrows represent magnetic spins of $\mathrm{Fe}^{3+}$ ions) and surrounding $\mathrm{Fe}^{2+}$ (blue - light gray in print - arrows) couple to the $\mathrm{Fe}^{3+}$ cluster leading to a net "ferromagnetic" moment. Mainly $\mathrm{Fe}^{2+}$ ions at the rim of a Fe ${ }^{3+}$ cluster contribute to the net moment. The large blue arrow to the right of the panel shows resulting magnetization. (b) $\mathrm{Fe}^{3+}$ ions in Ilm80 form antiferromagnetic clusters. Most surrounding $\mathrm{Fe}^{2+}$ ions couple magnetically to $\mathrm{Fe}^{3+}$ clusters. As spin frustration may exist, especially further away from the clusters, the ferromagnetic alignments of $\mathrm{Fe}^{2+}$ moments may not be complete in zero field. The large blue arrow below the panel indicates the net magnetization.

The results presented above support the cation distribution and magnetic properties model schematically illustrated in Fig. 2. In all samples, the $\mathrm{Fe}^{3+}$ ions are equally distributed on $\mathrm{A}$ and $\mathrm{B}$ layers and they couple antiferromagnetically to form $\alpha-\mathrm{Fe}_{2} \mathrm{O}_{3}$ clusters in an ilmenite-like matrix. In Ilm95 [Fig. 2(a)] the clusters have preferred sublattice magnetization along [111]. It is likely that the magnetic anisotropy of the ilmenite matrix stabilizes the magnetization direction of the clusters below its Néel temperature. Given the exchange constants in Ref. 34, an $\mathrm{Fe}^{2+}$ ion that has an $\mathrm{Fe}^{3+}$ ion as a nearest neighbor in the adjacent B layer is likely to couple magnetically to that $\mathrm{Fe}^{3+}$ cluster. Exchange energy equals about $-30 \mathrm{~K}$ per $\mathrm{Fe}^{2+}-\mathrm{Fe}^{3+}$ atom pair. For comparison, the antiferromagnetic coupling between $\mathrm{Fe}^{3+}$ pairs in hematite is about $-50 \mathrm{~K}$, and the ferromagnetic in-layer coupling between $\mathrm{Fe}^{2+}$ pairs in ilmenite is $\sim 10 \mathrm{~K}$. As the surrounding $\mathrm{Fe}^{2+}$ ions are in the A layers, they line up with parallel moments, and this leads to a net magnetization for each cluster [see Fig. 2(a)]. The effect arises because the antiferromagnetic modulation length of ilmenite is twice that of hematite and because of the strong antiferromagnetic coupling between iron ions in adjacent A and B layers. We can estimate the cluster sizes. We find that for a cluster moment of $150 \mu_{\mathrm{B}}$, corresponding to $\sim 38$ nearest-neighbor $\mathrm{Fe}^{2+}$ ions surrounding an $\alpha-\mathrm{Fe}_{2} \mathrm{O}_{3}$ cluster, that cluster will, depending on its shape, have a size (diameter) of $\sim 1-2 \mathrm{~nm}$.

In Ilm80 and Ilm70, the $\alpha-\mathrm{Fe}_{2} \mathrm{O}_{3}$ clusters interact and they have sublattice magnetization directions perpendicular to [111]. Magnetic order may be stabilized above $200 \mathrm{~K}$ by larger cluster sizes, exchange interactions between clusters (mediated by $\mathrm{Fe}^{2+}$ ions), and to lesser extent dipole interactions between clusters. In Fig. 2(b), the magnetic cluster structure for Ilm80 is illustrated schematically. Most $\mathrm{Fe}^{2+}$ ions in the sample are coupled to the clusters. The moments of $\mathrm{Fe}^{2+}$ ions that are nearest to a $\alpha-\mathrm{Fe}_{2} \mathrm{O}_{3}$ cluster are aligned in parallel due to the exchange coupling with $\mathrm{Fe}^{3+}$ in the cluster. The magnetization of $\mathrm{Fe}^{2+}$ ions further away from the $\alpha-\mathrm{Fe}_{2} \mathrm{O}_{3}$ clusters may be in a relaxed but frustrated state indicated in Fig. 2 by magnetic moments pointing at an oblique angle to [111]. If all $\mathrm{Fe}^{2+}$ spins are approximately parallel in an applied field, this leads to saturation moments of $2.67 \mu_{\mathrm{B}}$ and $2.15 \mu_{\mathrm{B}}$ per Fe ion in Ilm80 and Ilm70, respectively. This agrees with previous magnetic measurements: $\sim 2.8 \mu_{\mathrm{B}}$ and $\sim 2.2 \mu_{\mathrm{B}}$ per Fe for similar compositions. ${ }^{3}$ 


\section{CONCLUSIONS}

Our work provides evidence for the presence of hematite clusters with net magnetic moments due to surrounding $\mathrm{Fe}^{2+}$ in an ilmenite-like matrix. This is probably the clearest observation to date that antiferromagnetic clusters can behave perfectly ferrimagnetically because of exchange coupling to a normally antiferromagnetic matrix. Simultaneously, it shows how superparamagnetism and cluster-glass behavior can be established in ilmenite-hematite solid solutions. In comparison with the preliminary cluster description originally suggested by Ishikawa ${ }^{17}$ based on magnetic measurements of quenched hematite-ilmenite solid solutions, and supported by subsequent work, ${ }^{6,7,24}$ our results yield an atomic-scale explanation of the macroscopic magnetic properties observed in this system.

\section{ACKNOWLEDGMENTS}

We thank Tiziana Boffa Ballaran for x-ray diffraction measurements and analysis. C.F. and S.M. acknowledge funding from the Danish Council for Independent Research, Technology and Production Sciences (FTP) and Natural Sciences (FNU). S.A.M. acknowledges funding from the $\mathrm{Na}$ tional Research Council of Norway (NFR) and Bayerisches Geoinstitut. *fraca@fysik.dtu.dk

${ }^{1}$ T. Nagata, Nature (London) 172, 850 (1953).

${ }^{2}$ Y. Ishikawa and S. Akimoto, J. Phys. Soc. Jpn. 12, 1083 (1957).

${ }^{3}$ R. M. Bozorth, D. E. Walsh, and A. J. Williams, Phys. Rev. 108, 157 (1957).

${ }^{4}$ G. Shirane, S. J. Pickart, R. Nathans, and Y. Ishikawa, J. Phys. Chem. Solids 10, 35 (1959).

${ }^{5}$ G. Shirane, D. E. Cox, W. J. Takei, and S. L. Ruby, J. Phys. Soc. Jpn. 17, 1598 (1962).

${ }^{6}$ Y. Ishikawa, N. Saito, M. Arai, Y. Watanabe, and H. Takei, J. Phys. Soc. Jpn. 54, 312 (1985).

${ }^{7}$ B. Burton, P. Robinson, S. A. McEnroe, K. Fabian, and T. B. Ballaran, Am. Mineral. 93, 1260 (2008).

${ }^{8}$ R. B. Hargraves, J. Geophys. Res. 64, 1565 (1959).

${ }^{9}$ P. Robinson, R. J. Harrison, S. A. McEnroe, and R. B. Hargraves, Nature (London) 418, 517 (2002).

${ }^{10}$ S. A. McEnroe, P. Robinson, F. Langenhorst, C. Frandsen, M. P. Terry, and T. B. Ballaran, J. Geophys. Res. 112, B10103 (2007).

${ }^{11}$ C. Frandsen, S. Mørup, S. A. McEnroe, P. Robinson, and F. Langenhorst, Geophys. Res. Lett. 34, L07306 (2007).

${ }^{12}$ S. A. McEnroe, B. Carter-Stiglitz, R. J. Harrison, P. Robinson, K. Fabian, and C. McCammon, Nat. Nanotechnol. 2, 631 (2007).

${ }^{13}$ H. Hojo, K. Fujita, K. Tanaka, and K. Hirao, Appl. Phys. Lett. 89, 142503 (2006).

${ }^{14}$ T. Fujii, M. Kayona, Y. Takada, M. Nakanishi, and J. Takada, Solid State Ionics 172, 289 (2004).

${ }^{15}$ W. H. Butler, A. Bandyopadhyay, and R. Srinivasan, J. Appl. Phys. 93, 7882 (2003).

${ }^{16}$ T. Ericsson, A. Krisnhamurthy, and B. K. Srivastava, Phys. Scr. 33, 88 (1986).

${ }^{17}$ Y. Ishikawa, J. Phys. Soc. Jpn. 17, 1835 (1962).

${ }^{18}$ G. A. Sawatzky, F. Van Der Woude, and A. H. Morrish, Phys. Rev. 187, 747 (1969).

${ }^{19}$ S. Mørup, P. H. Christensen, and B. S. Clausen, J. Magn. Magn.
Mater. 68, 160 (1987).

${ }^{20}$ F. Bødker, M. F. Hansen, C. B. Koch, K. Lefmann, and S. Mørup, Phys. Rev. B 61, 6826 (2000).

${ }^{21}$ S. Mørup, D. E. Madsen, C. Frandsen, C. R. H. Bahl, and M. F. Hansen, J. Phys.: Condens. Matter 19, 213202 (2007).

${ }^{22}$ B. P. Burton, Ph. D. thesis, State University of New York at Stony Brook, 1982.

${ }^{23}$ M. F. Hansen, C. B. Koch, and S. Mørup, Phys. Rev. B 62, 1124 (2000).

${ }^{24}$ M. Arai, Y. Ishikawa, N. Saito, and H. Takai, J. Phys. Soc. Jpn. 54, 781 (1985).

${ }^{25}$ Q. A. Pankhurst and R. J. Pollard, J. Phys.: Condens. Matter 2, 7329 (1990).

${ }^{26}$ R. W. Grant, R. M. Housley, and S. Geller, Phys. Rev. B 5, 1700 (1972).

${ }^{27}$ P. Robinson, K. Fabian, and S. A. McEnroe, Geochem., Geophys., Geosyst. 11, Q05Z17 (2010).

${ }^{28}$ R. J. Harrison, Geochem., Geophys., Geosyst. 10, Q02Z02 (2009).

${ }^{29}$ C. Frandsen and S. Mørup, J. Phys.: Condens. Matter 18, 7079 (2006).

${ }^{30}$ T. S. Berquó, J. J. Erbs, A. Lindquist, R. L. Penn, and S. K. Banerjee, J. Phys.: Condens. Matter 21, 176005 (2009).

${ }^{31}$ F. Bødker, M. F. Hansen, C. B. Koch, and S. Mørup, J. Magn. Magn. Mater. 221, 32 (2000).

${ }^{32}$ C. R. H. Bahl, K. Lefmann, L. T. Kuhn, N. B. Christensen, H. Váquez, and S. Mørup, J. Phys.: Condens. Matter 18, 11203 (2006).

${ }^{33}$ P. J. van der Zaag, Y. Ijiri, J. A. Borchers, L. F. Feiner, R. M. Wolf, J. M. Gaines, R. W. Erwin, and M. A. Verheijen, Phys. Rev. Lett. 84, 6102 (2000).

${ }^{34}$ R. J. Harrison, S. A. McEnroe, P. Robinson, B. Carter-Stiglitz, E. J. Palin, and T. Kasama, Phys. Rev. B 76, 174436 (2007). 